\title{
ANALISIS KUALITATIF PERILAKU MASYARAKAT TERHADAP PENCEGAHAN PENYAKIT FILARIASIS DI DESA MATANG PELAWI
}

\author{
Masriana $^{1)}$, Juliandi ${ }^{2)}$, Iman Muhammad ${ }^{3)}$ \\ ${ }^{1}$ Mahasiswa Prodi S2 Kesehatan Masyarakat, Institut Helvetia Medan, Indonesia \\ ${ }^{2,3}$ Dosen Prodi S2 Kesehatan Masyarakat, Institut Helvetia Medan, Indonesia \\ Email: niswahray20@gmail.com
}

Diterima: September 2019, Diterbitkan: Desember 2019

\begin{abstract}
Abstrak
Filariasis (kaki gajah) merupakan penyakit infeksi yang bersifat menahun, disebabkan cacing filaria dan ditularkan oleh nyamuk. Perilaku masyarakat yang kurang higiene diduga menjadi penyebab terjadinya penularan filariasis. Tujuan penelitian ini untuk menganalisis secara kualitatif perilaku masyarakat terhadap pencegahan penyakit filariasis. Jenis Penelitian ini adalah penelitian kualitatif. Penelitian dilakukan di Desa Matang Pelawi Puskesmas Peureulak. Informan penelitian sebanyak 5 orang. Analisis data secara kualitatif dengan tahapan data reduction, data display, dan conclusion or verification. Hasil penelitian menunjukkan bahwa pengetahuan masyarakat Desa Matang Pelawi tentang penyakit filariasis dan pencegahannya, sebagian sudah paham, sebagian masyarakat lainnya kurang mengerti tentang penyebab, penularan, tanda dan gejala, pencegahan dan pengobatannya. Sikap masyarakat tentang penyakit filariasis, ada yang menganggap penyakit medis karena dapat mengenai siapa saja dan ada juga yang menganggap penyakit non medis atau karena hal gaib/mistis. Sebagian masyarakat bersikap negatif dengan mengejek, menghina dan menginginkan agar penderita filariasis diasingkan dari desa mereka karena dapat membawa musibah buruk bagi warga lainnya. Tindakan masyarakat sebagian paham tentang penyakit filariasis, dengan melakukan pencegahan seperti menjaga kebersihan lingkungan tempat tinggal, tidur menggunakan kelambu, dan minum obat pada Bulan Eliminasi Kaki Gajah (BELKAGA) pada bulan Oktober setiap tahunnya. Kesimpulan penelitian bahwa perilaku masyarakat berkaitan dengan pengetahuan, sikap, dan tindakan sebagian sudah baik karena sudah mendapatkan penyuluhan dari tenaga kesehatan.
\end{abstract}

Kata Kunci: Perilaku Masyarakat, Filariasis

\section{Abstract}

Filariasis is a chronic infectious disease, caused by filarial worms and transmitted by mosquitoes. Filariasis can cause permanent disability in the form of enlargement of the legs, arms, pouches of the testicles, breasts and genitals, attacking parents, children, men and women. The behavior of people who lack hygiene is thought to be the cause of filariasis transmission. The purpose of this study is to analyze qualitatively the behavior of people towards the prevention of filariasis. This type of research is qualitative research. The study was conducted in Matang Pelawi Village Peureulak Health Center. Research informants were 9 people. Qualitative data analysis with data reduction stages, data displays, and conclusion or verification. The result showed that the knowledge of the Matang Pelawi Village community about filariasis disease and its prevention, some of them already understood and understood the occurrence of filariasis in patients, while some other people did not understand the causes, transmission, signs and symptoms, prevention and treatment. The attitude of the Matang Pelawi Village community about filariasis, some consider medical illness because it can affect anyone and some consider non-medical illness or because of black magic such as being qualified, useless, witchcraft. Some people have a negative attitude by mocking, insulting and wanting filariasis sufferers to be displaced from their village because it can bring bad disaster to other resident. The actions of the Matang Pelawi Village community are partly understood about filariasis, by taking precautions such as maintaining the cleanliness of the living environment, sleeping using mosquito nets, and taking medicine on the Elephant Leg Elimination 
Month (BELKAGA) in October each year. The conclusion of the study is that people's behavior related to knowledge, attitude, and actions is partly good because they have received counseling from health workers Peureulak Public Health Center needs to improve health promotion activities about filariasis disease and its prevention so that all communities in the Peureulak Health Center work area can understand filariasis disease and take appropriate precautions.

\section{Keyword : Behavior, Society, Filariasis}

\section{PENDAHULUAN}

Penyakit filariasis (kaki gajah) merupakan penyakit infeksi yang bersifat menahun disebabkan cacing filaria dan ditularkan oleh nyamuk (Kemenkes RI, 2015). Menurut WHO, penduduk dunia yang terinfeksi oleh filariasis sekitar 120 juta dan menyerang sekitar 25 juta laki-laki dan 15 juta wanita. Filariasis menyerang 1.103 juta orang di 73 negara yang berisiko filariasis. Kasus filariasis menyerang $57 \%$ di Asia Tenggara dan $37 \%$ penduduk di wilayah Afrika. Sedangkan sisanya di wilayah Amerika, Mediterania Timur dan wilayah barat Pasifik (Muhsin, Safarianti, \& Maryatun, 2017).

Filariasis menyebar di seluruh wilayah Indonesia, di beberapa daerah mempunyai tingkat endemisitas yang cukup tinggi. Kasus kronis filariasis tahun 2015, kasus filariasis menurun menjadi 13.032 kasus dari 14.932 pada tahun 2014 yang menyebar di 34 provinsi(Kemenkes RI, 2017). Filariasis tersebar di seluruh Indonesia dengan prevalensi klinis sebesar 1,1\%o (rentang: 0,36,4\%o) (Kemenkes RI, 2013).

Data Riskesdas (2013) menunjukkan bahwa persentase penderita filariasis di Provinsi Aceh berada dalam urutan pertama terbesar dari seluruh provinsi di Indonesia yaitu sebesar 6,4\% (Kemenkes RI, 2013). Hal tersebut menunjukkan bahwa penyakit filariasis menjadi ancaman kesehatan bagi masyarakat yang ada di Provinsi Aceh (Pramono, Maryani, \& Wulandari, 2014). Kabupaten Aceh Timur terdapat 67 orang penderita filariasis. Pemerintah Kabupaten Aceh Timur melalui Dinas Kesehatan memberikan obat pencegahan massal filariasis bagi masyarakat. Tahun 2015 hanya $73 \%$ penduduk yang mau minum obat filariasis (Acehprov, 2016). Hasil survei yang dilakukan Kemenkes RI masih ditemukan microfilaria dalam darah sebagian masyarakat Kabupaten Aceh Timur, sehingga hal itu dinilai berpotensi terjadi peningkatan kasus (Ismail, 2017).

Pencegahan filariasis dilakukan dengan menghindari gigitan nyamuk infektif dan memberantas risiko yang berhubungan dengan kejadian filariasis misalnya yang berasal dari lingkungan dan perubahan perilaku masyarakat serta dapat mempertahankan dan mengembangkan kearifan lokal. Mengidentifikasi vektor dengan mendeteksi adanya larva infektif dalam nyamuk dengan menggunakan umpan manusia (Arsin, 2016).

Berdasarkan teori Hendrik L. Blum (1974) dalam Notoatmodjo, terdapat empat faktor yang mempengaruhi status kesehatan manusia, yaitu: lingkungan, perilaku, pelayanan kesehatan dan keturunan. Diantara keempat faktor tersebut, faktor perilaku masyarakat memiliki pengaruh besar terhadap pencegahan penyakit menular termasuk filariasis. Perilaku tersebut menurut Benyamin Bloom (1908) mencakup tiga domain, yaitu pengetahuan (knowledge), sikap (attitude), dan tindakan atau praktik (practice) (Nototatmodjo, 2015).

Berdasarkan data yang diperoleh dari Puskesmas Peureulak bahwa pada tahun 2017 ditemukan jumlah penderita filariasis sebanyak 6 orang yaitu 1 orang di Desa Snb. Peusangan, 1 orang di Desa Lhok Dalam, 1 orang di Desa Damartutong, 1 orang di Desa Uteun Dama, dan 3 orang di Desa Matang Pelawi. Jumlah penduduk di wilayah kerja Puskesmas Peureulak sebanyak 36.369 jiwa yang terdiri dari 11.853 orang laki-laki, dan 13.547 perempuan, dan jumlah kepala keluarga sebanyak 7986 KK. Kegiatan Pemberian Obat Pencegahan Massal (POPM) filariasis (kaki gajah) yang dilakukan di wilayah kerja Puskesmas Peureulak Kabupaten Aceh Timur masih terkendala karena sebagian masyarakat tidak seluruhnya bersedia minum obat

Survei pendahuluan pada masyarakat Desa Matang Pelawi dengan melakukan 
observasi terhadap lingkungan dan perilaku masyarakat Desa Matang Pelawi, diperoleh hasil sementara bahwa kondisi desa dengan lingkungan yang kurang bersih dan kurang sehat. Pepohonan yang rimbun di lingkungan sekitar rumah-rumah penduduk diduga menjadi tempat bersarangnya nyamuk penyebab filariasis berkembang biak yang telah terinfeksi cacing filaria. Jamban dan kamar mandi yang kebanyakan berada di luar rumah, tetapi saluran air kurang baik, karena terdapat genangan air dari buangan air kamar mandi. Barang-barang bekas di sekitar rumah banyak yang terbuka dengan genangan air hujan yang menjadi tempat berkembang baiknya vektor nyamuk seperti di kalengkaleng bekas minuman, botol-botol plastik, dan lain-lain. Kebersihan lingkungan juga kurang terjaga dengan banyaknya daun yang berserakan di sekitar rumah, beberapa rumah bahkan kondisi tempat tinggalnya lembab karena berdekatan dengan rawa-rawa. Demikian juga dengan parit yang melewati Desa Matang Pelawi terlihat kotor, airnya keruh, sampah-sampah plastik dan kaleng berserakan di parit. Banyak rumah yang tidak menggunakan kawat kasa.

Artikel ini bertujuan untuk menganalisis perilaku masyarakat meliputi pengetahuan, sikap, dan tindakan dalam pencegahan penyakit filariasis.

\section{METODE PENELITIAN}

Jenis Penelitian ini adalah kualitatif. Penelitian dilakukan di Desa Matang Pelawi Puskesmas Peureulak. Adapun subyek dalam penelitian ini adalah seluruh masyarakat Desa Matang Pelawi. Dalam penelitian ini subyek dibagi dua kategori yaitu informan utama dan informan triangulasi sebanyak 5 orang (3 orang informan utama dan 2 orang informan pendukung). Karakteristik informan utama adalah 1 orang anggota keluarga penderita filariasis (kaki gajah), dan 2 orang masyarakat di lingkungan tempat tinggal penderita. Sedangkan informan triangulasi adalah 1 orang petugas kesehatan dan 1 orang Kepala Puskesmas Peureulak. Analisis data dilakukan secara analisis tematik dengan tahapan data reduction, data display, dan conclusion or verification.

\section{HASIL DAN PEMBAHASAN}

\section{Karakteristik Informan}

Informan dalam penelitian ini sebanyak 5 orang yang terdiri dari 3 orang masyarakat, 1 orang petugas puskesmas, dan 1 orang kepala Puskesmas Peureulak. Karakteristik informan penelitian ini sebanyak 5 orang, yang berumur antara 28 tahun sampai dengan 50 tahun. Sebanyak 3 orang adalah perempuan dan 2 orang laki-laki. Pendidikan terakhir informan yaitu 2 orang berpendidikan SMP, 1 orang berpendidikan SMA, dan 1 orang berpendidikan S-1, 1 orang berpendidikan S2. Berdasarkan pekerjaan, sebanyak 2 orang adalah ibu rumah tangga, 1 orang petani, pegawai puskesmas, kepala Puskesmas Peureulak.

\section{Pengetahuan Masyarakat tentang Filariasis dan Pencegahannya}

Pengetahuan masyarakat Matang Pelawi tentang penyakit filariasis dan pencegahannya belum merata. Hal tersebut terbukti dari jawaban Informan yang diwawancarai bahwa mereka lebih mengenal kaki gajah atau kaki bengkak dibandingkan dengan filariasis, mereka masih asing dengan istilah filariasis untuk penyakit kaki gajah. Seperti yang dikatakan oleh informan 1 dan informan 2 . Tetapi informan 3 tahu bahwa filariasis adalah kaki yang membesar. Hal tersebut diperkuat oleh tenaga kesehatan di Puskesmas Peureulak bahwa masyarakat di wilayah kerja Puskesmas Peureulak seperti di Desa Matang Pelawi banyak yang kurang mengetahui tentang filariasis tetapi jika dikatakan sakit kaki gajah, sebagian masyarakat mungkin sudah mengetahuinya.

Hal tersebut sesuai dengan pendapat dari Santoso, bahwa orang masih asing dengan istilah filariasis, dan di beberapa daerah penyakit filariasis dikenal dengan istilah bahasa daerah setempat seperti "tubuk" atau "ular-ularan" atau ada juga yang menyebut "kelenjaran", sedangkan di daerah Baturaja, Sumatera Selatan istilah filariasis disebut dengan "Untut". Istilah filariasis secara medis kurang dikenal oleh masyarakat, istilah kaki gajah lebih sering didengar oleh masyarakat (Santoso, 2017).

Berdasarkan hasil penelitian tentang asal informasi yang diperoleh Informan tentang penyakit filariasis diketahui bahwa informan ada yang sudah mendapatkan informasi dari 
tenaga kesehatan dan ada yang belum pernah mendapatkan informasi dari tenaga kesehatan tentang filariasis. Informan 1 mengatakan sumber informasi tentang penyakit filariasis dari tenaga kesehatan, Informan 2 mengatakan tidak pernah mendapatkan informasi tentang filariasis, Menurut Informan 4 bahwa tidak semua wilayah dapat tercover penyuluhan filariasis sehingga masyarakat ada yang tahu dan ada yang tidak tahu tentang filariasis.

Masih banyaknya masyarakat yang berpengetahuan kurang tentang penyakit kaki gajah, disebabkan karena informasi yang diterima oleh semua masyarakat tentang penyakit kaki gajah ini sangatlah kurang, disebabkan akses informasi mengenai penyakit tersebut juga sangat terbatas. Terbatasnya akses informasi pada masyarakat, dan rendahnya tingkat pengetahuan masyarakat terutama masyarakat yang tinggal di pedesaan menyebabkan tingkat pengetahuan mereka tentang penyakit filariasis juga masih rendah (Arsin, 2016).

Berdasarkan hasil penelitian yang dilakukan Suryaningtyas \& Santoso (2012) pada Masyarakat Kecamatan Madang Suku III Kabupaten Oku Timur diketahui bahwa pengetahuan masyarakat kurang baik mengenai penyebab, gejala, proses penularan serta pencegahan filariasis. Pengetahuan masyarakat terhadap filariasis limphatik dapat ditingkatkan dengan memberikan penyuluhan oleh petugas kesehatan. Upaya penyuluhan kesehatan terhadap masyarakat bertujuan agar masyarakat mengetahui upaya untuk pencegahan dan pemberantasan filariasis secara tepat.

Penelitian Veridiana \& Chadijah, (2015) berkaitan dengan pengetahuan masyarakat tentang filariasis di Kabupaten Mamuju Utara masih sangat rendah. Hasil wawancara menunjukkan bahwa semua responden tidak mengetahui penyebab filariasis. Hampir semua responden $(98 \%)$ tidak mengetahui bahwa nyamuk merupakan penular filariasis. Begitu juga dengan gejala yang dialami oleh penderita filariasis, $90 \%$ responden tidak mengetahui gejalanya. Sebagian besar responden tidak mengetahui bahwa penyakit ini bisa diobati dengan penanganan medis dan dapat dicegah dengan berbagai cara misalnya dengan cara menghindari gigitan nyamuk.
Sejalan dengan penelitian yang dilakukan Nasrin (2012) bahwa pengetahuan masyarakat tentang filariasis masih kurang. Responden tidak mengetahui penyebab, gejala maupun penular filariasis. Ketidaktahuan responden tentang hal-hal yang mendasar dari penyakit ini menyebabkan mereka tidak tahu cara mencegah penularan penyakit ini.

Menurut peneliti, berdasarkan hasil penelitian ini menunjukkan bahwa pengetahuan masyarakat tentang penyakit filariasis dan pencegahan masih kurang. Terbukti dari jawaban-jawaban yang diberikan dari hasil wawancara sebagian masyarakat mengetahui penyebab, tanda gejala, pencegahan dan pengobatan penyakit kaki gajah. Tetapi masih ada juga masyarakat yang tidak paham tentang penyakit filariasis dan cara melakukan pencegahannya karena ia merasa bahwa bukan keluarga yang terkena penyakit tersebut sehingga merasa tidak perlu melakukan pencegahan. Hal tersebut juga disebabkan oleh tingkat pendidikan masyarakat di Desa Matang Pelawi sebagian masih berpendidikan rendah atau dasar yaitu tingkat pendidikan SD, dan SMP. Selain karena tingkat pendidikan yang rendah, akses informasi yang terbatas juga menyebabkan pemahaman masyarakat tentang penyakit filariasis juga terbatas. Peran pemerintah melalui Dinas Kesehatan Kabupaten Aceh Timur dan Puskesmas Peureulak untuk terus menggalakkan promosi kesehatan melalui penyuluhan di setiap desa yang ada di wilayah kerja Puskesmas Peureulak sehingga semua masyarakat mendapatkan akses informasi tentang penyakit filariasis, penyebab, penularan, tanda dan gejala, pencegahan, dan pengobatannya.

\section{Sikap Masyarakat tentang Pencegahan Penyakit Filariasis}

Berdasarkan hasil penelitian menunjukkan bahwa sikap masyarakat dalam pencegahan penyakit filariasis masih ada yang bersikap negatif, walaupun ada juga yang bersikap positif. Hasil wawancara dengan Informan diketahui bahwa sikap informan yang positif ditunjukkan oleh Informan 1 dan Informan 3 yang mengatakan bahwa merasa kasihan dengan penderita filariasis karena penyakit tersebut sulit untuk disembuhkan dan bersyukur pihak puskesmas 
sudah memberikan pengobatan kepada penderita. Informan 2 memiliki sikap negatif terhadap penderita kaki gajah dan mengatakan bahwa hal tersebut disebabkan oleh karena penderita pernah berbuat jahat sehingga akhirnya diguna-guna. Pihak Puskesmas Peureulak sendiri melalui Informan 4 sebagai tenaga kesehatan selalu berupaya memberikan informasi yang benar tentang penyakit filariasis, bahwa penyakit tersebut adalah penyakit medis, bukan non medis. Pihak Puskesmas Peureulak terus berupaya untuk memberikan penyuluhan agar pemahaman masyarakat menjadi lebih baik dan tidak bersikap negatif terhadap penderita filariasis.

Sebagian masyarakat beranggapan bahwa penyakit kaki gajah (elephantiasis atau filariasis) merupakan suatu penyakit yang berhubungan dengan keturunan (genetika), jampi-jampi, melakukan kesalahan (dosa), atau kutukan karena mendatangi tempat-tempat yang dilarang (Nwoke, Nwoke, Ukaga, \& Nwachukwu, 2010). Banyak orang masih beranggapan bahwa filariasis itu penyakit keturunan atau penyakit kutukan. Berdasarkan hasil survey yang pernah kami lakukan, ada masyarakat yang beranggapan bahwa filariasis terjadi karena terkena tulah atau kualat akibat waktu berjalan di hutan kakinya masuk ke dalam lubang dan tidak menutup lubang tersebut sehingga kaki orang yang masuk lubang menjadi besar. Ada juga yang menganggap bahwa itu penyakit kutukan dan keturunan, karena keluarga orang tersebut pernah melakukan kesalahan di masa lampau sehingga orang yang menderita penyakit ini biasanya diasingkan dari lingkungannya (Santoso, 2017). Berdasarkan hasil penelitian Suryaningtyas \& Santoso (2012) menunjukkan bahwa sikap responden telah menunjukkan sikap yang positif. Hal ini ditunjukkan dengan bersedia diambil darah untuk pemeriksaan filariasis serta perlunya keterlibatan masyarakat dalam pemberantasan filariasis. Program pemberantasan filariasis harus didukung oleh peran serta masyarakat, karena tanpa adanya peran serta masyarakat program tersebut tidak akan mencapai sasaran. Berdasarkan hasil penelitian Veridiana, hasil wawancara mengenai sikap menunjukkan bahwa sebagian besar responden setuju filariasis merupakan penyakit yang berbahaya, bukan merupakan penyakit keturunan. (Veridiana \& Chadijah, 2015).

Sikap negatif masyarakat terhadap penderita filariasis disebabkan adanya stigma yang berkembang di kalangan masyarakat tentang penyakit menular, bahkan stigma berkembang sangat cepat sehingga dapat membuat psikologis seorang pasien yang menderita penyakit menular menjadi terganggu dan mengakibatkan memperburuk keadaan penyakit pasien tersebut. Penyakit menular yang banyak dijumpai di kalangan masyarakat memiliki perkembangan stigma yang hampir sama dalam bentuknya dan perlakuannya di sebuah komunitas masyarakat. Sikap negatif masyarakat terhadap penderita penyakit menular biasanya ditunjukkan dengan cara mengejek, menghina, mencemooh, dan mengasingkan penderita tersebut dari pergaulan di masyarakat (Gerungan, 2014).

Menurut peneliti, hasil penelitian ini menunjukkan bahwa sikap masyarakat terhadap penderita filariasis dan pencegahannya masih ada yang bersikap negatif. Hal ini disebabkan oleh karena sebagian masyarakat tidak memahami tentang penyebab terjadinya filariasis. Masih ada anggapan masyarakat bahwa terjadinya pembengkakan pada kaki disebabkan oleh karena terkena guna-guna, kualat, atau karena memiliki sikap jahat pada orang lain, sehingga oleh orang yang dijahati tersebut penderita diguna-guna sehingga kakinya menjadi besar. Sikap yang salah tersebut disebabkan oleh kebiasaan masyarakat di Desa Matang Pelawi yang mengaitkan masalah-masalah penyakit dengan kejadiankejadian mistis. Sebagian masyarakat tidak percaya bahwa terjadinya pembesaran pada kaki penderita filariasis dapat dijelaskan secara medis, melalui cacing filaria yang ditularkan oleh semua jenis nyamuk. Banyak dari mereka yang menunjukkan sikap bahwa penderita filariasis sebaiknya diasingkan atau dipindahkan dari desa mereka, karena takut akan terkena dampak atau musibah karena perbuatan dari penderita filariasis tersebut. Masyarakat Desa Matang Pelawi masih banyak yang berpandangan bahwa akibat dari perbuatan satu orang, maka satu desa dapat terkena dampaknya, seperti terkena angin 
puting beliung, banjir bandang, gempa bumi, dan lain-lain.

Tenaga kesehatan di Puskesmas Peureulak perlu terus menerus memberikan informasi kepada warga masyarakat terutama di Desa Matang Pelawi bahwa penyakit kaki gajah (filariasis) adalah penyakit yang disebabkan secara medis, dan bukan karena hal gaib. Promosi kesehatan dengan melakukan penyuluhan secara rutin dan berulang kepada masyarakat diharapkan akan mampu merubah sikap masyarakat yang negatif menjadi positif, dan tidak lagi mengejek, menghina, mencemooh, atau mengasingkan penderita filariasis.

\section{Tindakan Masyarakat tentang Pencegahan Penyakit Filariasis}

Berdasarkan hasil penelitian menunjukkan bahwa tindakan pencegahan yang dilakukan oleh informan agar terhindar dari penyakit filariasis yaitu dengan memakai kelambu dan membersihkan lingkungan rumah dan air yang tergenang di sekitar rumah, seperti yang dilakukan oleh Informan 1 dan Informan 3. Sedangkan Informan 2 mengatakan tidak perlu melakukan pencegahan karena mereka sekeluarga tidak ada yang mengalami kaki bengkak. Menurut Informan 4, sebagian masyarakat sudah tahu cara melakukan pencegahan karena sudah mendapatkan informasi dari tenaga kesehatan, sedangkan sebagian lainnya tidak tahu cara melakukan pencegahan dengan benar. Menurutnya, untuk pencegahan filariasis dapat dilakukan dengan cara : tidur menggunakan kelambu, lubang angin (ventilasi) rumah ditutup kawat kasa halus, memasang obat nyamuk, memakai obat gosok anti nyamuk, membersihkan tempat-tempat perindukan nyamuk, melakukan penyemprotan untuk membunuh nyamuk dewasa, Mengikuti program pengobatan massal filariasis di puskesmas, Memeriksa diri ke puskesmas atau dokter bila tetangga atau keluarga terkena filariasis.

\section{Penggunaan kelambu}

Penggunaan kelambu pada masyarakat di Desa Matang Pelawi masih kurang, walaupun nyamuk banyak terdapat di wilayah desa tersebut, dengan kondisi lingkungan rumah yang ditumbuhi banyak pepohonan, dan juga pembuangan saluran air yang tergegang di sekitar rumah. Kegiatan masyarakat yang jarang menggunakan kelambu karena kebiasaan selama ini memang mereka lebih senang tidur tidak menggunakan kelambu, ada juga beberapa warga masyarakat yang tidak memiliki uang untuk membeli kelambu.

Hasil penelitian Veridiana \& Chadijah (2015), tindakan responden terhadap filariasis dalam kaitannya dengan penularan filariasis masih kurang. Sebagian besar masyarakat mempunyai kebiasaan keluar malam, tidur tidak menggunakan kelambu.

\section{Penggunaan obat nyamuk}

Penggunaan obat nyamuk oleh masyarakat Desa Matang Pelawi dalam upaya pencegahan filariasis sebagian masih kurang. Udara yang dingin di Desa Matang Pelawi menyebabkan masyarakat terbiasa tidur tidak menggunakan obat anti nyamuk baik obat nyamuk bakar maupun oles. Sebagian masyarakat lainnya menggunakan obat nyamuk bakar atau oles yang mudah dibeli di warung. Beberapa masyarakat yang jarang atau tidak menggunakan obat nyamuk beralasan tidak banyak nyamuk di rumahnya, kalau pun ada tetapi mereka meyakini nyamuk tersebut tidak menularkan penyakit.

Hasil penelitian Veridiana \& Chadijah (2015), tindakan responden dalam kaitannya pencegahan filariasis masih kurang yaitu tidak menggunakan anti nyamuk bakar. Penelitian Agustianingsih (2013) di Kelurahan Kertoharjo diketahui bahwa responden yang menutup rapat badan (memakai baju panjang dan celana panjang) saat keluar rumah pada malam hari, terbanyak adalah dengan memakai obat anti nyamuk oles atau lotion saat keluar rumah. Dan bentuk praktik pencegahan yang paling sedikit dilakukan adalah dengan menutup rapat badan (memakai baju dan celana panjang) saat keluar rumah pada malam hari.

\section{Membersihkan perindukan nyamuk}

Tindakan pencegahan filariasis oleh masyarakat dapat dilakukan dengan cara membersihkan tempat-tempat perindukan nyamuk, menutup barang-barang bekas, menguras tempat-tempat penampungan air, penyemprotan massal, menggunakan pelindung diri saat bekerja di kebun misalnya menggunakan baju lengan panjang, menggunakan obat anti nyamuk, menggunakan kelambu di saat tidur, tidak keluar di saat malam hari, menutup ventilasi dengan kawat kasa, dan menggunakan obat nyamuk bakar 
maupun semprot atau mengolesi kulit dengan obat anti nyamuk (Agrawal, 2015).

Tindakan pencegahan penyakit filariasis dilakukan pemerintah melalui program eliminasi penyakit kaki gajah (ELKAGA) yang bertujuan untuk menurunkan prevalensi menjadi kurang dari $1 \%$ melalui pengobatan massal sekali setahun selama 5 tahun di daerah yang endemis dan penatalaksanaan kasus klinis sehingga tidak menjadi masalah kesehatan masyarakat lagi. Dalam pelaksanaannya berbagai permasalahan perilaku dapat dijumpai diantaranya adalah: Beberapa pengambil keputusan di daerah belum memahami kerugian akibat penyakit kaki gajah sehingga belum memprioritaskan kegiatan sehingga biaya operasional tidak/kurang mencukupi. Adanya efek samping pengobatan menyebabkan masyarakat tidak mau melanjutkan pengobatan sampai tuntas. Kurangnya peran serta masyarakat dalam mencegah penyakit kaki gajah misalnya dengan cara menghindarkan diri dari gigitan nyamuk, menghilangkan tempat berkembangbiak nyamuk dan memeriksakan diri ke Puskesmas bila ada tanda-tanda penyakit kaki gajah.

\section{Kepatuhan Minum Obat}

Program BELKAGA, belum berjalan seperti yang diharapkan karena sebagian masyarakat tidak patuh dalam mengonsumsi obat yang diberikan petugas kesehatan. Hal ini disebabkan oleh karena mereka tidak yakin dengan khasiat obat, takut efek samping obat, bosan harus terus minum obat. Selain itu ada anggapan bahwa mereka tidak sakit sehingga tidak perlu mengonsumsi obat.

Penelitian Munawwaroh menunjukkan bahwa terdapat beberapa faktor yang mempengaruhi perilaku patuh minum obat masyarakat Kelurahan Kuripan Yosorejo RW I-V yaitu : Orang memiliki rasa takut terhadap penyakit kaki gajah, setelah melihat gambar spanduk, Orang memiliki kesadaran terhadap kesehatan dirinya dan anggota keluarganya, Terdapat anggota keluarga dengan background pendidikan kesehatan (faktor pendidikan), Harus ada kejadian terlebih dahulu sehingga akan patuh minum obat filariasis (Munawwaroh \& Pawenang, 2016)

Tindakan pencegahan yang dilakukan oleh informan berkaitan dengan minum obat yang dilakukan setiap tahun sejak 2016 pada bulan Oktober, Informan 1 mengatakan bahwa pada tahun 2016 ia tidak minum obat karena tidak diberi obatnya sementara ia sedang pergi ke Kuala Simpang, baru pada tahun 2017 ia minum obat yang dibagikan pada kegiatan Pemberian Obat Pencegahan Massal (POPM). Tetapi pada tahun 2018 ini, ia tidak minum obat karena sedang hamil. Informan 2 tidak pernah minum obat sejak tahun 2016, karena merasa tidak perlu minum obat, dalam keluarga tidak ada yang terkena penyakit kaki gajah. Informan 3 minum obat, karena sudah tahu manfaat dari kegiatan POPM tersebut. Menurut Informan 4, kegiatan pencegahan filariasis dengan mengonsumsi obat sudah dilakukan selama 2 tahun berturut-turut (2016 dan 2017), tetapi pada kegiatan tersebut masih banyak masyarakat yang tidak datang dengan alasan sibuk bekerja, ada yang memang tidak mau datang pada kegiatan tersebut karena merasa tidak perlu, ada yang tidak mau karena memang tidak bisa minum obat (takut minum obat), ada juga yang beralasan karena ada efek samping dari obat tersebut seperti muntah dan pusing. Pemberian obat disesuaikan dengan usia orang tersebut, dan biasanya jika tidak datang obat dititipkan pada kader untuk diberikan pada masyarakat yang tidak datang, tetapi apakah obat tersebut dikonsumsi atau tidak, tidak bisa dipastikan karena tidak dikontrol saat minum obatnya.

\section{Promosi Kesehatan}

Sebelum kegiatan pemberian obat pencegahan massal (POMP) yang dilakukan setiap tahun di wilayah kerja Puskesmas Peureulak, kegiatan didahului dengan promosi kesehatan tentang penyakit filariasis (kaki gajah), seperti yang sudah dilakukan pada tahun 2017 oleh tenaga kesehatan Puskesmas Peureulak yaitu selama 3 bulan sebelum kegiatan Bulan Eliminasi Penyakit Kaki Gajah (BELKAGA) yaitu pada bulan Agustus, September, Oktober 2017. Kegiatan promosi kesehatan melalui penyuluhan kesehatan di wilayah kerja Puskesmas Peureulak dengan menggunakan leaflet, spanduk, baliho, dan video, tetapi karena minimnya sarana prasarana di setiap desa dan luasnya wilayah Puskesmas Peureulak menyebabkan kegiatan promosi kesehatan tersebut tidak dapat menjangkau seluruh masyarakat di wilayah puskesmas Peureulak. Hasilnya, tidak semua masyarakat dapat 
dijangkau dan akhirnya pengetahuan, sikap, dan tindakan sebagian masyarakat di wilayah kerja Puskesmas Peureulak terutama di Desa Matang Pelawi masih banyak yang kurang.

\section{SIMPULAN}

1) Pengetahuan masyarakat Desa Matang Pelawi tentang penyakit filariasis dan pencegahannya, sebagian sudah paham dan mengerti terjadinya penyakit filariasis pada penderita, sedangkan sebagian masyarakat lainnya kurang mengerti tentang penyebab, penularan, tanda dan gejala, pencegahan dan pengobatannya.

2) Sikap masyarakat Desa Matang Pelawi tentang penyakit filariasis, ada yang menganggap penyakit medis karena dapat mengenai siapa saja dan ada juga yang menganggap penyakit non medis atau karena hal gaib/mistis (black magic) seperti kualat, diguna-guna, santet. Sebagian masyarakat memiliki sikap negatif dengan mengejek, menghina dan menginginkan agar penderita filariasis dipindahkan (diasingkan) dari desa mereka karena dapat membawa musibah buruk bagi warga lainnya.

3) Tindakan masyarakat Desa Matang Pelawi yang sudah paham tentang penyakit filariasis, dengan melakukan pencegahan seperti menjaga kebersihan lingkungan tempat tinggal, tidur menggunakan kelambu, dan minum obat pada Bulan Eliminasi Kaki Gajah (BELKAGA) pada bulan Oktober setiap tahunnya.

\section{UCAPAN TERIMA KASIH}

Peneliti mengucapkan terima kasih kepada LPPM Institut Kesehatan Helvetia Medan yang telah mendukung rangkaian penelitian ini, Enumerator penelitian. Teristimewa pada seluruh informan yang telah berpartisipasi dalam penelitian ini

\section{DAFTAR PUSTAKA}

Acehprov. (2016). Pencegahan Filariasis Berlanjut di 2016.

Agrawal, C. (2015). Lymphatic Filariasis In India: Problems, Challenges And New Iniᄀtiatives. Medical Journal Armed Forces India, 62(4), 359-362.
Agustianingsih, D. (2013). Praktik Pencegahan Filariasis. KEMAS, 8(2), 190-197.

Arsin, A. (2016). Epidemiologi Filariasis di Indonesia (Cetakan I). Makassar: Masagena Press.

Gerungan, W. (2014). Psikologi Sosial (Cetakan 3). Bandung: Refika Aditama.

Ismail, I. (2017). Cegah Kaki Gajah, Warga Aceh Timur Diberi Filariasis.

Kemenkes RI. (2013). Riset Kesehatan Dasar tahun 2013. Jakarta: Kementerian Kesehatan Republik Indonesia.

Kemenkes RI. (2015). Buku Saku Kader Kesehatan, Mengenali dan Mencegah Penyakit Kaki Gajah (Filariasis). Jakarta: Kementerian Kesehatan Republik Indonesia.

Kemenkes RI. (2017). Filariasis, Menuju Eliminasi Filariasis 2020. Jakarta: Pusat Data dan Informasi Epidemiologi Kementerian Kesehatan Republik Indonesia.

Muhsin, Safarianti, \& Maryatun. (2017). Peran sel granulosit pada penyakit filariasis. Jurnal Kedokteran Syiah Kuala, 17(1), 43-53.

Munawwaroh, L., \& Pawenang, E. T. (2016). Evaluasi Program Eliminasi Filariasis dari Aspek Perilaku dan Perubahan Lingkungan. Unnes Journal of Public Health, 5(3), 195-204.

Nasrin. (2012). Faktor-Faktor Lingkungan dan Perilaku yang Berhubungan dengan Kejadian Filariasis di Kabupaten Bangka Barat. Universitas Diponegoro.

Nototatmodjo, S. (2015). Promosi kesehatan dan Perilaku Kesehatan (Cetakan V). Jakarta: Rineka Cipta.

Nwoke, B., Nwoke, E., Ukaga, C., \& Nwachukwu, M. (2010). Epidemiological characteristics of Bancroftian filariasis and the Nigerian environment. Journal of Public Health and Epidemiology, 2(6), 113-117.

Pramono, M. S., Maryani, H., \& Wulandari, P. (2014). Analisis Kasus Penyakit Filariasis di Provinsi Nangroe Aceh Darussalam Dengan Pendekatan Metode Zero Inflatedpoisson (ZIP) Regression. Buletin Penelitian Sistem Kesehatan, 17(1), 35-44.

Santoso. (2017). Mengenal Filariasis.

Suryaningtyas, N., \& Santoso. (2012). 
Pengetahuan, Sikap Dan Perilaku Masyarakat Kecamatan Madang Suku III Kabupaten Oku Timur Tentang Filariasis Limfatik. Jurnal Ekologi Kesehatan, 11(1), 251-257.

Veridiana, N. N., \& Chadijah, S. (2015). Pengetahuan, Sikap Dan Perilaku
Masyarakat Terhadap Filariasis di Kabupaten Mamuju Utara, Sulawesi Barat. Buletin Penelitian Kesehatan. Buletin Penelitian Kesehatan, 43(1), 47-54. 